\title{
Tropospheric water vapour above Switzerland over the last 12 years
}

\author{
J. Morland ${ }^{1}$, M. Collaud Coen ${ }^{2}$, K. Hocke ${ }^{1,3}$, P. Jeannet ${ }^{2}$, and C. Mätzler ${ }^{1,3}$ \\ ${ }^{1}$ Institute of Applied Physics, University of Bern, Sidlerstrasse 5, 3012 Bern, Switzerland \\ ${ }^{2}$ MétéoSuisse, Station aérologique, 1530 Payerne, Switzerland \\ ${ }^{3}$ Oeschger Centre for Climate Change Research, University of Bern, Sidlerstrasse 5, 3012 Bern, Switzerland
}

Received: 8 December 2008 - Published in Atmos. Chem. Phys. Discuss.: 18 March 2009

Revised: 29 July 2009 - Accepted: 11 August 2009 - Published: 19 August 2009

\begin{abstract}
Integrated Water vapour (IWV) has been measured since 1994 by the TROWARA microwave radiometer in Bern, Switzerland. Homogenization techniques were used to identify and correct step changes in IWV related to instrument problems. IWV from radiosonde, GPS and sun photometer (SPM) was used in the homogenisation process as well as partial IWV columns between valley and mountain weather stations. The average IWV of the homogenised TROWARA time series was $14.4 \mathrm{~mm}$ over the 1996-2007 period, with maximum and minimum monthly average values of $22.4 \mathrm{~mm}$ and $8 \mathrm{~mm}$ occurring in August and January, respectively. A weak diurnal cycle in TROWARA IWV was detected with an amplitude of $0.32 \mathrm{~mm}$, a maximum at 21:00 UT and a minimum at 11:00 UT. For 19962007, TROWARA trends were compared with those calculated from the Payerne radiosonde and the closest ECMWF grid point to Bern. Using least squares analysis, the IWV time series of radiosondes at Payerne, ECMWF, and TROWARA showed consistent positive trends from 1996 to 2007. The radiosondes measured an IWV trend of $0.45 \pm 0.29 \% / y$, the TROWARA radiometer observed a trend of $0.39 \pm 0.44 \% / y$, and ECMWF operational analysis gave a trend of $0.25 \pm 0.34 \% / y$. Since IWV has a strong and variable annual cycle, a seasonal trend analysis (Mann-Kendall analysis) was also performed. The seasonal trends are stronger by a factor 10 or so compared to the full year trends above. The positive IWV trends of the summer months are partly compensated by the negative trends of the winter months. The strong seasonal trends of IWV on regional scale underline the necessity of long-term monitoring of IWV for detection, understanding, and forecast of climate change effects in the Alpine region.
\end{abstract}

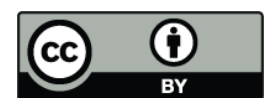

Correspondence to: C. Mätzler (matzler@iap.unibe.ch)

\section{Introduction}

Water vapour is the strongest natural greenhouse gas. Under the assumption of constant relative humidity, the Clausius Clapeyron equation predicts a water vapour increase of $6 \%$ per degree Kelvin increase in atmospheric temperature. Model simulations have shown that the water vapour feedback effect amplifies the temperature increase due to rising greenhouse gas concentrations (e.g. Hall and Manabe, 1999).

Ross and Elliott (1996) analyzed surface to $500 \mathrm{mb}$ Integrated Water Vapour (IWV) calculated from North American radiosonde data. Significant increases of 0.3 to $0.7 \% / y$ were observed over a large part of North America for the 1975 to 1995 period. However, a similar study carried out for the whole of the Northern Hemisphere for the 1973 to 1995 period (Ross and Elliott, 2001), showed that the radiosonde IWV trends for Europe were smaller, often negative and not significant at the $95 \%$ level.

Nilsson and Elgered (2008) studied IWV data from 33 Swedish and Finnish Global Positioning System (GPS) stations from 1996-2006. Trends lay between -0.05 and $+0.1 \mathrm{~mm} / \mathrm{y}(-0.14$ and $+0.75 \% / \mathrm{y})$ with errors of around $0.04 \mathrm{~mm} / \mathrm{y}$. The IWV increase was larger in summer than in winter, when negative trends were frequently observed.

Trenberth et al. (2005) examined the European Centre for Medium-Range Weather Forecasts (ECMWF) 40year reanalysis (ERA-40) data for the 1988 to 2003 period and found no significant trends over Europe. However, a global average trend of $0.04 \pm 0.009 \mathrm{~mm} / \mathrm{y}$, equivalent to $0.13 \pm 0.03 \% / y$, was calculated for the same period using Special Sensor Microwave Imager (SSM/I) satellite observations over the oceans. Morland et al. (2006) compared IWV of ERA-40 with GPS station data at Jungfraujoch (3584 m above sea level, a.s.l., Switzerland) and found a high correlation $\left(r^{2}>0.9\right)$ between both data sets.

Ground based microwave radiometers make accurate measurements of water vapour at a high temporal resolution (one

Published by Copernicus Publications on behalf of the European Geosciences Union. 
minute or less). They also offer an independent source of atmospheric information from both radiosonde and analysis data. However, there are few long term datasets. Water vapour observations from microwave radiometers and other instruments have been collected by the US Atmospheric Radiation Program (ARM) since the mid 1990s (Revercomb et al., 2003). A radiometer based in Onsala, Sweden has been operating on a campaign basis since 1980 and on a continual basis since 1993. By combining the radiometer data with other datasets, Haas et al. (2003) estimated an IWV trend of $0.17 \pm 0.01 \mathrm{~mm} / \mathrm{y}$ from 1980 to 2002 .

This paper presents IWV measured by the TROWARA microwave radiometer in Bern, Switzerland for 1994-2007. The TROWARA instrument is explained in Sect. 2 as well as other instruments and datasets which are used for the IWV trend study. Section 3 describes the homogenization of the radiometer data. Section 4 compares the TROWARA 1996 to 2007 monthly and diurnal climatology with other instruments. In Sect. 5, IWV trends calculated from the homogenized TROWARA dataset are compared with those obtained from radiosonde and ECMWF data.

\section{Data sources}

\subsection{TROWARA}

The TROpospheric WAter RAdiometer (TROWARA) is located at $\left(46.95^{\circ} \mathrm{N}, 7.44^{\circ} \mathrm{E}, 575 \mathrm{~m}\right.$ a.s.l. $)$ and measures water vapour at a $2 \mathrm{~s}$ time resolution using observations of the thermal microwave emission at $21.3 \mathrm{GHz}$, near a water vapour line, and at $31.5 \mathrm{GHz}$, in the water vapour continuum. The use of the second frequency helps to determine the amount of cloud liquid water present. Hourly average measurements were used in the present analysis. The original instrument was described by Peter and Kämpfer (1992) and details of the IWV retrieval are given in Ingold and Mätzler (2000). The instrument operated outdoors from 1994 to April 2002. In November 2002, an improved radiometer model was introduced (Morland, 2002) and TROWARA was re-installed in an indoor laboratory with a microwave transparent window. This move reduced the diurnal cycle in the internal air temperature by around $80 \%$ and also meant that the instrument was completely sheltered from rain (Morland, 2007).

Measurements of IWV are now possible during light rain conditions of up to $2.4 \mathrm{~mm} \mathrm{~h}^{-1}$. However, in order to maintain consistency with the old measurements, all observations made during rain were excluded from the present analysis. A rain flag was set when integrated liquid water (ILW) exceeded $0.5 \mathrm{~mm}$ or when a rain gauge at Bern measured precipitation greater than 0 . If high ILW or precipitation was detected according to this criterion, the TROWARA data within a time interval of \pm 15 min were not used for the trend analysis.
Deuber et al. (2005) compared IWV from TROWARA with coincident measurements of a GPS receiver. The mean difference TROWARA-GPS was $-0.10 \mathrm{~mm}$, and the standard deviation of TROWARA-GPS was $1.35 \mathrm{~mm}$.

\subsection{Radiosonde}

The Swiss RadioSonde (SRS400) at Payerne (490 ma.s.l. and $40 \mathrm{~km}$ southwest of Bern) makes twice daily soundings starting at 11:00 and 23:00 UT. The resistive carbon hygristor used for the humidity measurements was manufactured by VIZ until 1999 and thereafter by Sippican (Jeannet et al., 2004). The response time of the humidity sensor strongly increases at the low temperatures encountered in the middle to upper troposphere. Furthermore, this sensor is unable to measure in the dry stratosphere and overestimates water vapor in dry tropospheric layers (Miloshevich et al., 2006 and references therein), especially above low level stratus in the winter (Guerova et al., 2003).

A homogeneity test indicated a major break point in the midday to midnight IWV in 1995. Minor or secondary break points remain in the time series due to small changes in the treatment of the solar radiation error and differences between batches of hygristors delivered by the manufacturer. To avoid the major breakpoint, the present trend analysis is restricted to 1996-2007. However, the TROWARA homogenization is carried out for 1994-2007.

During a campaign in Payerne (5 November 2003 to 23 February 2004) with collocated instruments, Martin et al. (2006) found a dry bias of about $0.5 \mathrm{~mm}$ for GPS IWV measurements with respect to the Swiss RadioSonde (SRS400). On the other hand, the mean difference between radiometric and radiosonde IWV was less than $0.15 \mathrm{~mm}$.

\subsection{Sun photometer}

A sun photometer (SPM) was operated at Bern from 1993 to 2007. It tracked the sun and measured direct sunlight along the view direction in 18 different channels including one centred on the $946 \mathrm{~nm}$ water vapour absorption line. The water vapour transmittance can be determined after first accounting for aerosol effects. The transmittance is then converted into IWV using a method based on radiative transfer modelling (Ingold et al., 2000). For this study, hourly average data were used. The SPM is an accurate method but sampling is limited to daytime and clear skies. This introduces a negative fair weather bias in the IWV data, since cloudy conditions are often associated with higher IWV values. Nyeki et al. (2005) found a small dry bias of $0.4 \mathrm{~mm}$ of a precision filter radiometer (sun photometer) with respect to a GPS receiver at Davos in Switzerland.

\subsection{GPS}

Zenith Total Delay (ZTD) data for the fixed GPS receiver at Bern were obtained from Swisstopo for the period from 
November 2000. The IWV calculation followed the method described in Bevis et al. (1992). The Zenith Hydrostatic Delay (ZHD) due to dry gases in the atmosphere was estimated from pressure measurements. The Zenith Wet Delay, which is the delay due to water vapour, was calculated as ZWD = ZTD - ZHD. The ZWD can be converted to IWV using a relationship which uses the water vapour weighted mean atmospheric temperature, $T_{m}$. This quantity was estimated from surface temperature measurements. The standard deviation of IWV from colocated GPS receivers ranges from 0.4 to $0.7 \mathrm{~mm}$ (Vey et al., 2009). The accuracy or the systematic bias depends on the individual GPS station, the GPS IWV retrieval, and other factors. Wang et al. (2008) found a mean difference of matched radiosondes RS92 minus GPS receivers of about $-1 \mathrm{~mm}$ (for IWV range: 0 $25 \mathrm{~mm}$ ). Morland et al. (2006a) compared coincident measurements of a precision filter radiometer (PFR) and a GPS receiver at Jungfraujoch and got a mean difference PFR-GPS of $-1.4 \mathrm{~mm}$. Morland et al. (2006b) found mean differences PFR-GPS from -0.8 to $-1.8 \mathrm{~mm}$ for intercomparisons at Locarno, Payerne, and Davos. It remains an open question which measurement technique comes closer to the true IWV.

\subsection{ECMWF}

Profiles at 00:00, 06:00, 12:00 and 18:00 UT were extracted from the ECMWF operational analysis for the grid point closest to Bern $\left(7.87^{\circ} \mathrm{E}, 47.25^{\circ} \mathrm{N}\right)$ for $1996-2007$. IWV was calculated by integrating the data from 850 to $200 \mathrm{mb}$. The $850 \mathrm{mb}$ level was chosen as a starting point because it is the lowest level for which no data gaps occur. This pressure is lower than the average annual pressure at Bern of $952 \mathrm{mb}$ because the presence of nearby mountains increases the model topography. Actually it would be better to use ERA-40 data instead of ECMWF operational analysis, but ERA-40 data stopped in 2002. The trends for Switzerland calculated from the ECMWF operational analysis are in good agreement with IWV trends from NCEP reanalysis (Kistler et al., 2001) which we calculated as a control (not shown here). NCEP-NCAR are the National Centers for Environmental Prediction and the National Center for Atmospheric Research of the United States. The agreement of ECMWF operational analysis and NCEP-NCAR reanalysis shows that the IWV data are mainly driven by observations from the dense European radiosonde network.

\section{Homogenisation of TROWARA data}

Ingold and Mätzler (2000) noted a mean IWV bias of $+2.1 \mathrm{~mm}$ in TROWARA data relative to the Payerne radiosonde from 1995-1998. This was resolved in the year 2000 when an amplifier in the radiometer was replaced. A problem with the $31 \mathrm{GHz}$ hot load voltage measurement (see Sect. 3.2) occurred when the instrument was moved to

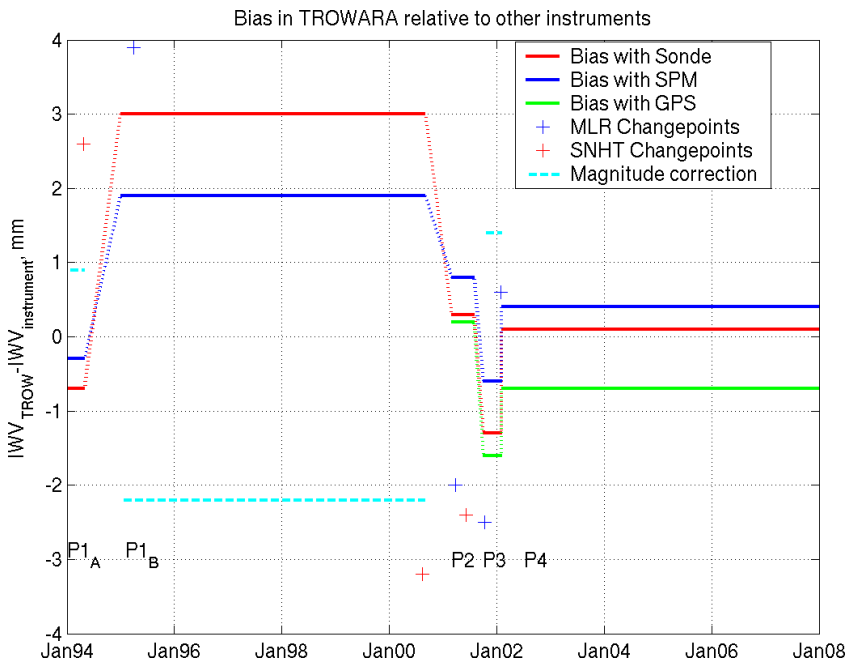

Fig. 1. The bias in TROWARA relative to Payerne radiosonde, Bern SPM and Bern GPS is plotted for five different homogeneous periods. The crosses show the changepoints detected by MLR (Multiple Linear Regression) and SNHT (Standard Normalization Homogenization Technique) near the beginning or end of each period. The dashed line shows the magnitude of the average correction calculated for P1A, P1B and P3.

the Netherlands for a field campaign in July 2001. This was recognized and the problem was solved on 4 February 2002.

The effect of these instrument problems on the measurements is illustrated in Fig. 1 which shows the mean bias in TROWARA relative to Payerne radiosonde, SPM and GPS averaged over five different periods. Matching hourly average values were used to calculate the bias between TROWARA and other instruments. From 4 February 2002 onwards (P4), the bias between TROWARA and other instruments is within $\pm 0.7 \mathrm{~mm}$, which is acceptable given the fact that the accuracy of the GPS is around $0.7 \mathrm{~mm}$ (Hagemann et al., 2003). The SPM tends to have a fair-weather negative bias, leading to a positive bias of $0.4 \mathrm{~mm}$ in TROWARA relative to SPM, because of cases where clouds prevented the SPM from observing during the whole of the hourly averaging period.

The first instrument problem is evident in P1B (April 1995 to August 2000) when TROWARA data had a bias of 1.9 and $3.0 \mathrm{~mm}$, relative to SPM and radiosonde, respectively. After the amplifier replacement, the instrument seemed to function well for a brief period P2 (March to July 2001) when the bias lay between 0.2 and $0.8 \mathrm{~mm}$. Measurements in Bern were interrupted by a field campaign and when the instrument returned in October 2001, the hot load voltage was frequently saturated. Despite removing all data for which the hot load voltage had actually reached $5 \mathrm{~V}$ (saturation), an average TROWARA bias of -0.6 to $-1.6 \mathrm{~mm}$ occurred in period P3 (October 2001 to 4 February 2002). This can be explained by the fact that the voltage cannot be accurately measured close 
to detector saturation, and is frequently under-estimated.

It is clear from Fig. 1 that the effects of a strong positive bias early in the series, followed by a negative bias in the middle will cause an error in any trend analysis applied to the original dataset. Given the scarcity of independent IWV observations stretching back more than ten years, it is worthwhile using homogenisation techniques to correct the TROWARA data. These are statistical techniques which were developed to deal with inhomogeneities in other climate data, principally precipitation and temperature observations. Abrupt changes in a time series of meteorological observations can be caused by either instrument problems or the removal of the instrument to a different site. Homogenisation techniques were developed to avoid losing large amounts of data which are potentially valuable for climatic analysis. In general, the instrument time series is compared to one or more reference series which should be in the same climatic region. If the reference series is well chosen, it should show the same climatic variations as the instrument series, and any differences will be due to artificial factors.

The Multiple Linear Regression (MLR) technique from Vincent (1998) and the Standard Normalization Homogenization Technique (SNHT) from Alexandersson (1986) were used to compare TROWARA IWV averaged over 5 day periods with three different reference series. The Payerne radiosonde was the only alternative source of tropospheric IWV. For intercomparison with IWV from TROWARA, the Payerne radiosonde profile was utilized from the altitude of TROWARA (575 m a.s.l.) up to the $200 \mathrm{hPa}$-pressure level (mean tropopause level: $\sim 210 \mathrm{hPa}$ ). As stratospheric IWV is about $0.02 \mathrm{~mm}$, i.e. about $0.15 \%$ of the mean IWV at Payerne and a value much smaller than the uncertainty of the series of the Payerne radiosondes, taking into account the stratospheric IWV would hardly have an influence on the present trend study. Monitoring of stratospheric humidity was started around 2005 in Bern. Future IWV trend studies of Payerne radiosondes could be refined by taking stratospheric IWV from the ground-based microwave radiometer MIAWARA at Bern (Haefele et al., 2008).

Reference series were created by calculating the IWV in the atmospheric layer between the pairs of weather stations Bern Liebefeld (556 ma.s.1.) and Bern Bantiger (1060 m a.s.1.), and Neuchâtel (485 m a.s.1.) and Zimmerwald (907 $\mathrm{m}$ a.s.1.). The Zimmerwald station is maintained by the Astronomical Institute at the University of Bern and the other data came from the MeteoSwiss networks. These stations are near to the TROWARA site, and we derived representative time series of lower tropospheric IWV from the hygrometer station data. Mätzler et al. (2002) found a strong correlation between IWV and the partial IWV column of the first $500 \mathrm{~m}$ from ground. The correlation coefficient $r$ was about 0.9. Thus, lower tropospheric IWV derived from nearby weather station pairs is well suited for the homogenisation of the TROWARA data set.
The yearly mean IWV values for these layers are 2.5 and $3.0 \mathrm{~mm}$ for Bern Liebefeld/Bern Bantiger and Neuchâtel/Zimmerwald, respectively, which is around $20 \%$ of the TROWARA yearly mean IWV of $14.5 \mathrm{~mm}$. The coefficient of determination $r^{2}$ is the square of the correlation coefficient $r$. The $r^{2}$ value between TROWARA five day average IWV and that calculated between weather station pairs is 0.86 , i.e. $86 \%$ of the TROWARA IWV variance can be explained by the weather station pairs. The $r^{2}$ value for the correlation between TROWARA and radiosonde fiveday average IWV is 0.89 . Although the IWV calculated between the weather stations covers only the lowest $50 \mathrm{mb}$ or so of the atmosphere, the correlation between these data and TROWARA over a 5 day averaging period is not a great deal less than the correlation between TROWARA and radiosonde IWV.

Super-imposed on Fig. 1 are the magnitudes of the significant changepoints found by the MLR and SNHT techniques. When the whole series was examined, the SNHT and MLR found significant negative changepoints in August 2000 and March 2001, respectively, which corresponded to the last measurements made before and the first measurements made after the replacement of the faulty amplifier. The series was then broken down into two sections before and after this break and retested.

When the first section was tested (January 1994 to August 2000), the SNHT and MLR found changepoints in April 1994 and April 1995, respectively, which corresponded to the measurements directly before and directly after a break in observations which lasted almost a year. Unfortunately, it was not possible to determine what instrument changes occurred in this period. However, it was assumed that they led to the amplifier problem which caused the positive bias during P1B. The first period of measurements, from January to April 1994 will be referred to as P1A. During this time, TROWARA had a negative bias of up to $-0.7 \mathrm{~mm}$.

The latter section of the data was dominated by a sudden negative bias in TROWARA relative to all other instruments due to the saturated hot load voltage. The SNHT detected a changepoint in June 2001, and the MLR estimated the time of the change more correctly to be October 2001, which was the time when TROWARA resumed measurements in Bern after the field campaign. The data from October 2001 to December 2007 were tested with both techniques. The SNHT failed to detect the expected positive changepoint at the end of the period affected by saturated hot load voltages. This was probably because the $31 \mathrm{GHz}$ atmospheric temperature was lower and close to the cold load brightness temperature, which would lead to little change in the IWV (see Sect. 3.2). However, the MLR did detect a significant positive change at the end of January 2001 of magnitude $+0.6 \mathrm{~mm}$. 


\subsection{Correction of amplifier problem}

Unfortunately the only information we have about TROWARA in the early years is that the original amplifier at $21 \mathrm{GHz}$ was replaced during a break in measurements which lasted from late August 2000 to March 2001. An earlier break in measurements occurred from May 1994 to April 1995 , but there is no record of what work was carried out on the instrument. Whatever repairs or improvements occurred, they must have affected the measurements, as indicated by Fig. 1 which shows a negative bias in TROWARA relative to other instruments in P1A and a positive bias in P1B.

The bias in TROWARA IWV relative to the sonde was plotted against TROWARA IWV for the time period P1B, and a negligible slope of $0.0017 \mathrm{~mm} / \mathrm{y}$ was found. It was therefore concluded that a constant correction was appropriate. This correction was calculated from the changes in bias relative to sun photometer and radiosonde at the end of P1B, $\Delta \mathrm{bSPM}_{\text {end }}$ and $\Delta$ bsonde $_{\text {end }}$, as well as the MLR and SNHT changepoints at the end of P1B, $\triangle \mathrm{MLR}_{\text {end }}$ and $\triangle \mathrm{SNHT}_{\text {end }}$. The change in bias and the changepoints at the start of $\mathrm{P} 1 \mathrm{~B}$ could not be used because they included the effect of the negative bias in P1A. The corrected IWV in P1B, IWV $\mathrm{IORP1B}_{\text {, }}$ was calculated from the original IWV measurements in P1B, IWV $\mathrm{ORIGP1B}_{\text {, as follows: }}$

$$
\begin{aligned}
& D_{\text {start }}=0.25( \Delta \mathrm{bSPM}_{\text {start }}+\Delta \text { bsonde }_{\text {start }}+\ldots \\
&\left.\ldots+\Delta \mathrm{MLR}_{\text {start }}+\Delta \mathrm{SNHT}_{\text {start }}\right) \\
& D_{\text {end }}=0.25\left(\Delta \mathrm{bSPM}_{\text {end }}+\Delta \text { bsonde }_{\text {end }}+\ldots\right. \\
&\left.\ldots+\Delta \mathrm{MLR}_{\text {end }}+\Delta \mathrm{SNHT}_{\text {end }}\right) \\
& \mathrm{IWV}_{\text {CORP1B }}= \\
&=\mathrm{IWV}_{\text {ORIGP1B }}+D_{\text {end }} \\
&=\mathrm{IWV}_{\text {ORIGP1B }}-2.2 \mathrm{~mm}
\end{aligned}
$$

The correction for P1A was calculated as the difference between the mean change $D_{\text {start }}$ at the start of P1B and the mean change $D_{\text {end }}$ at the end, as follows:

$$
\begin{aligned}
\mathrm{IWV}_{\text {CORP1A }} & =\mathrm{IWV}_{\text {ORIGP1A }}+D_{\text {start }}-D_{\text {end }} \\
& =\mathrm{IWV}_{\text {ORIGP1A }}+0.9 \mathrm{~mm} .
\end{aligned}
$$

\subsection{Correction of saturated hot-load problem}

An underestimate of IWV is what would be expected from the saturated hot load voltage problem. In order to calibrate the measurements, TROWARA measures a hot and cold load calibration target after every sky measurement. Each calibration cycle lasts just under two seconds. The antenna brightness temperature, $\mathrm{BT}_{\mathrm{ant}}$, can be calculated as follows:

$\mathrm{BT}_{\text {ant }}=T_{\text {hot }}+\frac{V_{\text {ant }}-V_{\text {hot }}}{V_{\text {hot }}-V_{\text {cold }}}\left(T_{\text {hot }}-T_{\text {cold }}\right)$
$\mathrm{BT}_{\mathrm{ant}}$ is later corrected to the true sky brightness temperature using a tipping calibration. $V_{\text {ant }}, V_{\text {hot }}$ and $V_{\text {cold }}$ are the antenna, hot and cold load voltages, respectively, and $T_{\text {hot }}$ and $T_{\text {cold }}$ are the physical temperatures of the cold $(24 \mathrm{~K})$ and hot $(312 \mathrm{~K})$ loads. A partial derivative with respect to $V_{\text {hot }}$ leads to:

$\frac{\partial \mathrm{BT}_{\mathrm{ant}}}{\partial V_{\mathrm{hot}}}=\frac{V_{\text {cold }}-V_{\mathrm{ant}}}{\left(V_{\text {hot }}-V_{\text {cold }}\right)^{2}}\left(T_{\text {hot }}-T_{\text {cold }}\right)$

If $V_{\text {ant }}$ is equal to $V_{\text {cold }}$ then a change in $V_{\text {hot }}$ will have no effect on $\mathrm{BT}_{\mathrm{ant}}$, all other things being equal. However, if $V_{\mathrm{ant}}$ is greater than $V_{\text {cold }}$, as was often the case since a vacuum cold load cooled to $24 \mathrm{~K}$ was used, then $\mathrm{BT}_{\text {ant }}$ will increase as the voltage decreases. The opposite is true if $V_{\text {ant }}$ is less than $V_{\text {cold. }}$. In other words, if we assume that the voltage is $5 \mathrm{~V}$ (maximum range) when it was in fact higher, then an artificial decrease in $V_{\text {hot }}$ is imposed which leads, under most sky conditions, to an artificial increase in $\mathrm{BT}_{\text {ant }}$. The IWV was calculated from the linearised brightness temperatures (Wu, 1979) as follows:

IWV $=-0.5059+0.4837 \cdot$ BTlin $_{21}-0.2151 \cdot$ BTlin $_{31}$

where BTlin 21 and BTlin 31 are the calibrated 21 and $31 \mathrm{GHz}$ linearised brightness temperatures in Kelvin. The equation comes from calculating IWV and linearised brightness temperatures from Payerne radiosonde data and then regressing the IWV against the simulated brightness temperatures. The constant -0.5059 in equation 5 was derived by means of a intercomparison of coincident TROWARA and GPS measurements (Rohrbach, 1999). Equation (5) indicates that an artificial increase in $\mathrm{BT}_{31}$ leads, under most atmospheric conditions, to an artificial decrease in IWV as is confirmed in Fig. 1.

The above theoretical analysis shows that we can expect a negative bias in IWV due to the saturated hot load problem, except in very cold atmospheric conditions when a positive bias will occur. It also indicates that the bias will be dependent on the IWV amount. A plot of the TROWARA bias relative to radiosonde and GPS data against IWV showed that the bias did indeed become increasingly negative with increasing IWV amount. From the best fit linear regression of TROWARA bias against IWV the following correction was estimated:

$\mathrm{IWV}_{\mathrm{CORP} 3}=-2.23+1.3967 \cdot \mathrm{IWV}_{\mathrm{ORIGP}}$

where IWV $\mathrm{V}_{\mathrm{CORP}}$ is the corrected TROWARA IWV in mm for period P3, and IWV $\mathrm{ORIGP}_{3}$ is the original TROWARA observation in $\mathrm{mm}$.

The corrections for P1A, P1B and P3 were applied to the TROWARA data. In order to confirm their validity, the homogenised dataset was compared with simultaneous sonde, SPM and GPS measurements for the period 1994-2007. The average bias in the corrected TROWARA data was +0.4 , 


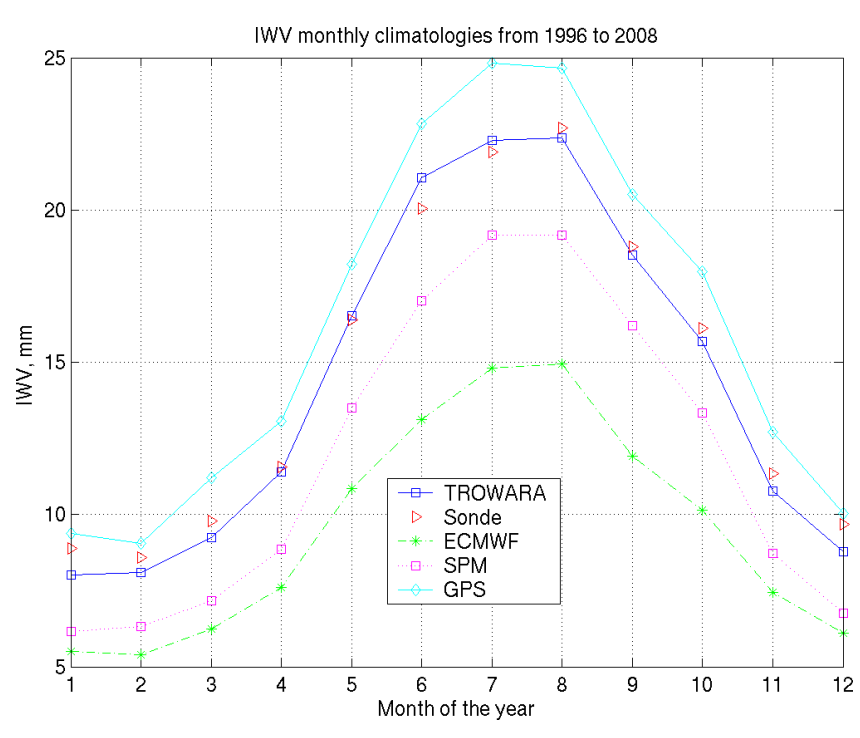

Fig. 2. IWV monthly climatologies from 1996 to 2007 from TROWARA, Payerne radiosonde integrated from $570 \mathrm{~m}$, ECMWF integrated between 850-200 mb, Bern SPM and Bern GPS.

+0.3 and $-0.6 \mathrm{~mm}$ for radiosonde, SPM and GPS, respectively. These small biases confirm the success of the homogenisation and indicate that the dataset is now ready for climatological studies and trend analysis, which will be described in the next two sections. It is emphasised that the bias between TROWARA and GPS was calculated for rainfree conditions.

\section{Climatology}

\subsection{Monthly climatology}

Figure 2 shows a comparison between the TROWARA 1996-2007 monthly climatology and that of the Payerne radiosonde integrated from the altitude of Bern. Also shown are IWV climatologies for the Bern GPS and SPM as well as for ECMWF data for the closest gridpoint to Bern, integrated from $850-200 \mathrm{mb}$. The average IWV of the homogenised TROWARA time series was $14.4 \mathrm{~mm}$ over the 1996-2007 period. Maximum and minimum monthly average values of $22.4 \mathrm{~mm}$ and $8 \mathrm{~mm}$ occurred in August and January, respectively.

TROWARA has a negative bias in every month relative to the co-located GPS instrument. This ranges from $-0.6 \mathrm{~mm}$ (February) to $-2.1 \mathrm{~mm}$ (July) and is on average $-1.4 \mathrm{~mm}$. This value is considerably larger than the bias of $-0.6 \mathrm{~mm}$ reported in Sect. 3.2 for the comparison between TROWARA and GPS matching hourly averages, i.e. non-raining conditions. The differences are due to the fact that the GPS monthly mean includes periods when the GPS made observations and TROWARA did not. This usually occurred during rainy periods since the TROWARA data shown here are re- stricted to rain-free conditions. The highest IWV values are likely to occur during rainy conditions when the atmosphere is close to saturation. This can be checked by examining the annual mean IWV for TROWARA data for 2003 to 2007. The value in non-raining conditions was $14.3 \mathrm{~mm}$. However, when measurements made in light rain conditions the annual mean was $14.6 \mathrm{~mm}$, with differences of up to $1.2 \mathrm{~mm}$ occurring between the datasets for individual months. Therefore the additional bias of $-0.8 \mathrm{~mm}$ in the TROWARA monthly means relative to GPS may be due to the sampling differences between a dataset which excludes rainy conditions and one which includes measurements made even during heavy precipitation. The maximum precipitation in Bern occurs in June and the minimum in March, which is close to the months (July and February) when the largest and smallest TROWARA bias relative to GPS occurs.

TROWARA has a slight positive bias relative to the sonde $(0.4$ to $1.0 \mathrm{~mm})$ in June and July, but otherwise has a negative bias ranging from -0.1 to $-0.9 \mathrm{~mm}$. The largest negative biases occur in December and January which is not surprising given the fact that the radiosonde has a tendency to overestimate IWV over low stratus in the winter. The mean TROWARA bias relative to the radiosonde is $-0.3 \mathrm{~mm}$, whereas a slight positive bias was seen in the matching hourly measurements in Sect. 3.2. The negative TROWARA bias in the monthly means is probably related to the fact that these include rainy periods when the radiosonde makes a measurement and TROWARA does not.

TROWARA has a positive bias of between 1.8 (January) and $4.1 \mathrm{~mm}$ (June) relative to the co-located SPM. The monthly mean comparison gives quite different results from the comparison between matching hourly average TROWARA and SPM data described in Sect. 3 where the TROWARA bias was just $0.3 \mathrm{~mm}$. This is because the SPM operates only in sunny, daylight conditions and therefore grossly undersamples the number of potential weather situations in a given month. The percentage bias in TROWARA relative to SPM has an average value of $19 \%$, and is lowest in September (12\%) and highest in January (24\%).

The sampling differences between the various measuring techniques can be better visualised with a histogram plot as shown in Fig. 3. The histograms are plotted as a percentage of the total number of measurements in each $1 \mathrm{~mm}$ bin in order to allow better comparison between different instrument types. For all instruments, IWV values between 1 to $2 \mathrm{~mm}$ have a frequency of less than $0.5 \%$, but values of 4 to $5 \mathrm{~mm}$ occur around 3 to $4 \%$ of the time. For the IWV range between 5 and $19 \mathrm{~mm}$, all instruments show a frequency between 4 and $6 \%$, with TROWARA and radiosonde showing a peak frequency between 8 and $10 \mathrm{~mm}$. The GPS distribution function tends to be more of a plateau shape, whilst the SPM shows double peaks at 5 and $16 \mathrm{~mm}$. The SPM makes $71 \%$ of its measurements in the 5 to $19 \mathrm{~mm}$ range, as opposed to the GPS which makes only $62 \%$ of its measurements in this range. At higher IWV values, the influence of 


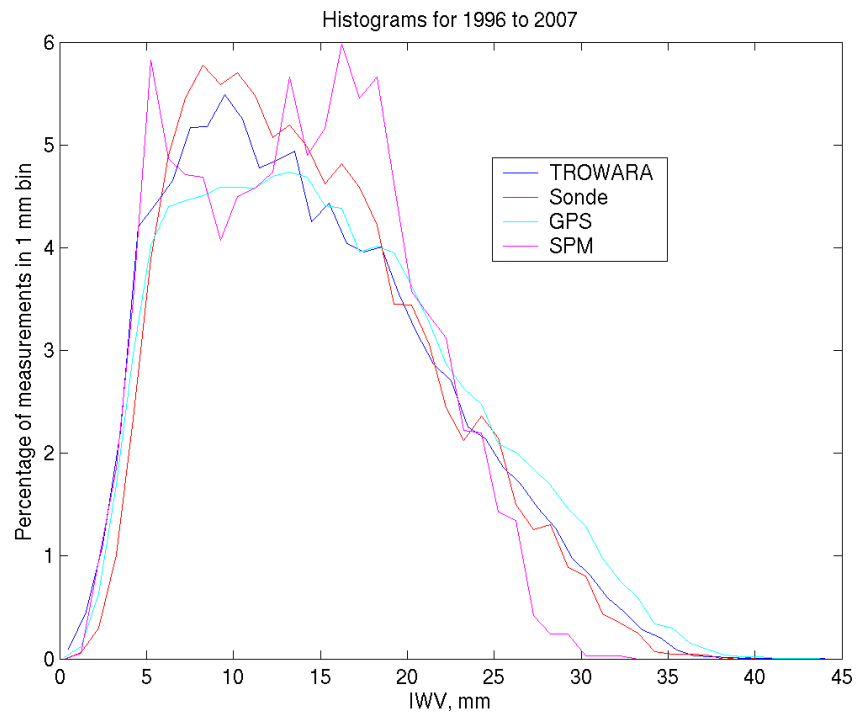

Fig. 3. Histograms plotted for all available hourly average TROWARA, GPS, Radiosonde and SPM measurements for the period 1996 to 2007. The radiosonde is integrated from the altitude of Bern.

the different sampling methods is evident. The GPS measures IWV values of $26 \mathrm{~mm}$ and above $11.6 \%$ of the time because it can measure in heavy rain conditions. However, IWV measurements in this range are recorded only $2.3 \%$ of the time by the SPM due to the restriction that it measures only in fair weather conditions. TROWARA and radiosonde measure IWV values above $26 \mathrm{~mm}$ around $7 \%$ of the time. There is a large divergence in the maximum IWV with values of 32.2, 39.5, 43.5 and $43.8 \mathrm{~mm}$ being recorded by SPM, radiosonde, TROWARA and GPS, respectively.

TROWARA has a positive bias relative to the ECMWF data (Fig. 2), but this is expected since these data are integrated from an altitude of $850 \mathrm{mb}$, whereas the mean annual pressure in Bern is around $100 \mathrm{mb}$ higher. The positive TROWARA bias varies between 2.5 and $8 \mathrm{~mm}$ depending on the time of year. However, it is always between 30 and $38 \%$ of the TROWARA IWV, with an average of 33\%. Thus around one third of the atmospheric water vapour over Bern is to be found in the first $100 \mathrm{mb}$ of pressure decrease. From the comparison between reference series and TROWARA in Sect. 3, we know that $20 \%$ of the total IWV lies in the layer between Neuchatel (average annual pressure $961 \mathrm{mb}$ ) and Zimmerwald (average annual pressure $913 \mathrm{mb}$ ). Therefore about $20 \%$ of the IWV lies in the first $50 \mathrm{mb}$ of pressure decrease.

\subsection{Diurnal cycle of IWV}

Because IWV has rapid time variations related to the synoptic weather situation, it is difficult to observe any diurnal cycle on a particular day. However, a diurnal cycle may be detectable over a longer period of time. In this section, emphasis will be given to comparing the diurnal cycle of the TROWARA and GPS IWV. For the calculation of IWV from GPS Zenith Wet Delay, an estimate of the water vapour weighted mean atmospheric temperature, $T_{m}$, is required. The standard formula for estimating $T_{m}$ from surface air temperature was developed by Bevis et al. (1992), and takes no account of the fact that the surface temperature has a much higher diurnal cycle amplitude than temperatures higher in the atmosphere. Wang et al. (2005) used $T_{m}$ estimated from ERA-40 reanalysis data and from the National Centers for Environmental Prediction and the National Center for Atmospheric Research (NCEP-NCAR) global reanalysis products to evaluate the suitability of using surface air temperature, $T_{s}$, to estimate $T_{m}$. They concluded that the large diurnal cycle in $T_{s}$ led to a dry bias in $T_{m}$ at night and in the early morning and a consequent dry bias in the GPS IWV during these times. In the case of Bern, the diurnal cycle of $T_{S}$ has an amplitude of $3.5 \mathrm{~K}$, whereas the amplitude of $T_{m}$ in central Europe calculated by Wang et al. (2005) from ERA-40 data lies between 0.5 and $1 \mathrm{~K}$.

For comparison with TROWARA, GPS IWV was calculated from $T_{S}$ using the observed diurnal cycle, a damped diurnal cycle and no diurnal cycle. The surface air temperature with a damped diurnal cycle, $T_{\text {sdamped, }}$ was defined as follows:

$T_{\text {sdamped }}=0.25 T_{S}+0.75 \overline{T_{S}}$

where $\overline{T_{S}}$ is the daily mean surface air temperature. This formula gave an average diurnal-cycle amplitude of $0.9 \mathrm{~K}$ for the years 2002 to 2007 .

Figure 4 shows the average hourly IWV for the period 2003 to 2007. Only data acquired since 2003 were considered because before then TROWARA had stood outdoors, and the daytime heating and night-time cooling inside the radiometer may have had an influence on the diurnal cycle of IWV. Another reason is that the GPS is only available from 2001 onwards. Also shown is the ECMWF hourly average IWV for 00:00, 06:00, 12:00 and 24:00 UT, and the radiosonde average IWV for 00:00 and 12:00 UT. For easier comparison, the ECMWF, GPS and radiosonde data are plotted minus a constant daily average bias with respect to TROWARA data. This bias was $-4.9,1.3$ and $0.3 \mathrm{~mm}$ for ECWMF, GPS and radiosonde, respectively.

The first point of interest is that although a diurnal cycle in IWV exists, it is very small with an amplitude of $0.32 \mathrm{~mm}$. The ECMWF data have a slightly larger diurnal amplitude than TROWARA $(0.39$ as opposed to $0.32 \mathrm{~mm})$ and seem to be consistent as to the position of the minimum and maximum. TROWARA shows a minimum at 11:00 UT, with a broad dip between 09:00 and 12:00 UT, and peak values occurring between 19:00 and 21:00 UT. These are close to the ECMWF minimum and maximum at 12:00 and 18:00 UT. The ECMWF data can, of course, only give a limited picture 


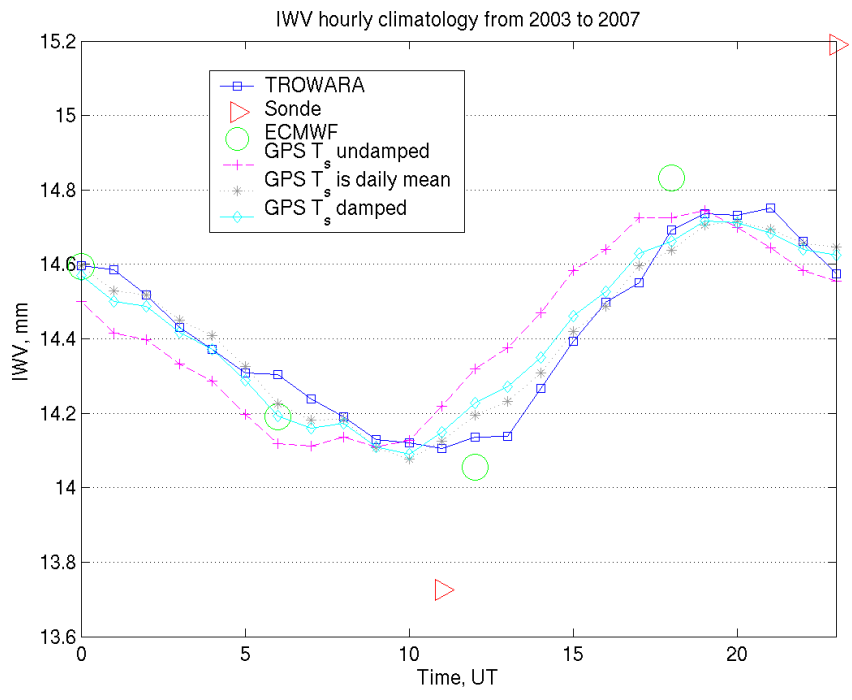

Fig. 4. Comparison of IWV diurnal climatologies for 2003 to 2007. For easier comparison, the sonde, ECMWF and GPS data are plotted less an average bias between these data and the TROWARA data. The GPS data are calculated using a full diurnal cycle, no diurnal cycle and a damped diurnal cycle in surface air temperature.

of the diurnal cycle because of the poor temporal resolution. Interestingly, Wang et al. (2005) find a consistent maximum at 18:00 UT for the water vapour weighted mean atmospheric temperature over central Europe using both NCEP-NCAR and ECMWF ERA-40 reanalysis data.

The radiosonde data are only twice daily and therefore give no detailed picture of the diurnal cycle. The minimum of the radiosonde IWV occurs at 11:00 UT, in agreement with TROWARA. The radiosonde IWV has a diurnal cycle amplitude of $0.73 \mathrm{~mm}$ which is about twice as large as that of TROWARA or ECMWF. Guerova et al. (2005) observed a stronger negative bias in Payerne radiosonde measurements relative to co-located GPS in the daytime than at night. Morland and Mätzler (2007) observed a stronger negative bias in Payerne radiosonde IWV relative to GPS in summer than in any other season. Both of these effects were attributed to an error caused by solar radiation. The large IWV diurnal cycle observed in the radiosonde is possibly related to this error.

The GPS shows a diurnal cycle amplitude of $0.32 \mathrm{~mm}$, in agreement with TROWARA. It also gives a detailed picture of the shape of the diurnal cycle, which clearly differs depending on how the surface air temperature is treated for the conversion between Zenith Wet Delay and IWV. If $T_{S}$ is used without any damping of the diurnal cycle, the GPS minimum and maximum occur around two hours earlier than TROWARA data. A negative bias in GPS ( $T_{s}$ undamped) IWV can be observed in Fig. 4 during the night and early morning (21:00 UT to 08:00 UT), in agreement with the findings of Wang et al. (2005). It is complimented by a positive bias in GPS ( $T_{s}$ undamped) IWV between 11:00 and 17:00 UT, which is almost certainly due to an unrealistically high estimate of $T_{m}$ from the undamped $T_{s}$. Damping or removing the diurnal cycle of $T_{s}$ shifts the GPS diurnal cycle to the right by one to two hours so that GPS values lie closer to TROWARA values. The absolute difference between the TROWARA and GPS diurnal cycle is $0.1 \mathrm{~mm}$ for the undamped $T_{s}$, and this reduces to 0.03 and $0.04 \mathrm{~mm}$, respectively, for totally and partially damped diurnal cycles in $T_{s}$.

Dai et al. (2002) examined the diurnal cycle of GPS data from 54 North American stations for 1996 to 2000 and found an amplitude of 1 to $1.8 \mathrm{~mm}$ in the summer and less than $0.8 \mathrm{~mm}$ in other seasons. Güldner and Spänkuch (1999) analysed the diurnal cycle of 2 years of radiometer data from Potsdam in Germany and also found a higher diurnal cycle amplitude in summer (around $1.5 \mathrm{~mm}$ ) than in winter (around $0.5 \mathrm{~mm}$ ). The summer values reported in these studies are substantially higher than the yearly values for Bern presented here, although the values for other seasons are more similar.

The peak in the IWV diurnal cycle occurs about $6 \mathrm{~h}$ later than the maximum daily temperature at Bern, which is reached at around 14:00 UT. The increase in IWV in the daytime must be related to daytime evaporation and the decrease at night to condensation of water vapour from the atmosphere. It would be interesting to check whether the amount of dew deposited on grass on a clear night corresponded to the amplitude of the diurnal cycle.

We should mention that the diurnal amplitude of IWV was modulated in time. Long intervals with rather weak amplitudes alternated with intervals of unexpected strong amplitudes. A separate study would reveal short-term variability and seasonal change of the diurnal cycle of IWV.

\section{Trend analysis}

A trend analysis was carried out on the homogenised TROWARA data using both least squares analysis (LSA) and the seasonal Mann Kendall (MK) technique (Hirsch and Slack, 1984). Both of these methods were applied by Collaud Coen et al. (2007) to 10.5 years of aerosol data from the high alpine site Jungfraujoch.

\subsection{Least squares analysis}

Since most trend studies avoid a detailed description of the LSA, it makes sense to present the matrix formulation of the LSA which we utilize for a decomposition of the IWV series into a constant term, a linear trend, and a seasonal term represented by a series of cosine and sine harmonics. The matrix formulation is valuable for a simple programming and understanding of the LSA.

The annual, semi-annual and ter-annual cosine and sine waves are sufficient for our purpose, since the main goal is the derivation of the linear trend. 
According to the addition theorem, $a \cos \omega t+b \sin \omega t$ is equal to the cosine wave $A \cos (\omega t-\varphi)$ with $\varphi=\operatorname{atan}(b, a)$ and $A=\sqrt{a^{2}+b^{2}}$. The expression $a \cos \omega t+b \sin \omega t$ is better than $A \cos (\omega t-\varphi)$ for building a linear equation system. After the LSA, amplitudes and phases of the annual harmonics could be calculated with the addition theorem as well as their errors.

The IWV series are represented by the column vector IWV. The solution vector $\mathbf{X}$ contains the unknown fit parameters of the basis functions. The basis functions are the columns of the design matrix A (Press et al., 1992). The noise vector $\mathbf{N}$ can be determined as soon as $\mathbf{X}$ has been estimated. The measurement times of the IWV series are at $t_{i}$ with $i=1, \ldots, n$. The frequencies are $\omega_{i}=2 \pi i /(1 \mathrm{y})$ with $i=1,2,3$ for the annual, semi-annual, and ter-annual oscillations respectively. The matrix formulation of the problem is as follows:

$\mathbf{I W V}=\left(\begin{array}{c}I W V\left(t_{1}\right) \\ I W V\left(t_{2}\right) \\ I W V\left(t_{3}\right) \\ \vdots \\ I W V\left(t_{n}\right)\end{array}\right) ; \quad \mathbf{X}=\left(\begin{array}{c}x_{1} \\ x_{2} \\ x_{3} \\ \vdots \\ x_{8}\end{array}\right) ; \quad \mathbf{N}=\left(\begin{array}{c}n\left(t_{1}\right) \\ n\left(t_{2}\right) \\ n\left(t_{3}\right) \\ \vdots \\ n\left(t_{n}\right)\end{array}\right)$

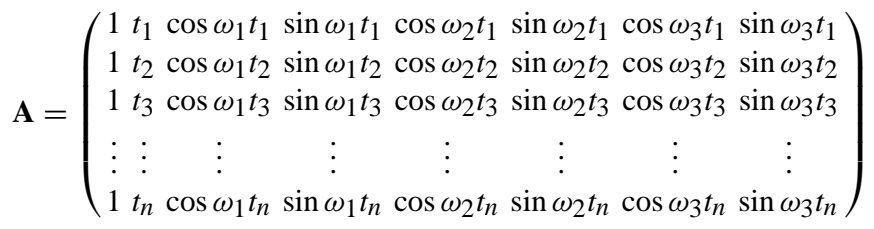

$\mathbf{I W V}=\mathbf{A} \cdot \mathbf{X}+\mathbf{N}$

The sum of the squares of the noise $n\left(t_{i}\right)$ is minimized when $\mathbf{X}$ is estimated as follows :

$\mathbf{I W V} \doteq \mathrm{A} \cdot \mathrm{X}$

$\mathbf{X}=\left(\mathbf{A}^{\prime} \cdot \mathbf{A}\right)^{-1} \cdot \mathbf{A}^{\prime} \cdot \mathbf{I W V}$.

Using a mathematical programming language, it is easy to transpose $\left(\mathbf{A}^{\prime}\right)$ and to invert the quadratic matrix $\left(\left(\mathbf{A}^{\prime} \cdot \mathbf{A}\right)^{-1}\right)$. The solution vector $\mathbf{X}$ provides the constant $x_{1}$, the linear trend (inclination $x_{2}$ of the straight line $x_{2} t$ ), and the amplitudes $x_{i}, x_{i+1}$ for $i=3,5,7$ of the cosine and sine waves of the annual, semi-annual and ter-annual variations. According to equation (15.4.15) in Press et al. (1992), the variance $\sigma^{2}\left(x_{i}\right)$ of the the fit parameter $x_{i}$ can be derived by means of the i-th diagonal element of the matrix $\left(\mathbf{A}^{\prime} \cdot \mathbf{A}\right)^{-1}$ for $i=1,2,3, \ldots 8$.

Following Weatherhead (2000), the LSA has been performed for the monthly mean series of IWV. In order to avoid unrepresentative values due to the gaps in the TROWARA data, a monthly mean was only calculated if measurements were available on at least 8 distinct days. The homogenized TROWARA dataset for the period since the start

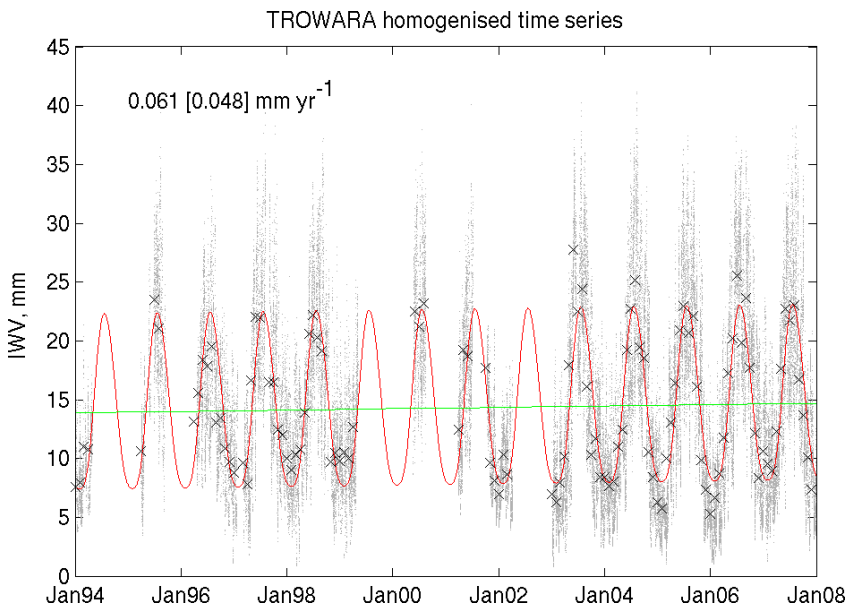

Fig. 5. TROWARA homogenized observations for 1994-2007 with a model of the seasonal cycle (red line) and trend estimate (green line). The grey dots show the hourly average observations and the crosses show the monthly average values.

of TROWARA measurements (1994-2007) is presented together with the LSA trend estimate in Fig. 5. It shows that TROWARA has measured continuously during the five years from 2003 to end 2007. There is also a fairly continuous period from 1996 through to 1998. However, Fig. 5 also shows the gaps which occurred due to a field campaign (summer 2001), and repairs and upgrades made on the instrument (latter half of 1994, spring 1999 to spring 2000, latter half of 2002). The LSA trend estimate is $0.061 \pm 0.048 \mathrm{~mm} / \mathrm{y}$. This represents an increase of around $4 \%$ per decade.

Figure 6 shows a comparison of the trend results in $\mathrm{mm} / \mathrm{y}$ for the shorter period 1996-2007 which avoids the main radiosonde inhomogeneity. The LSA trends are calculated for all times, as well as midday or midnight measurements. The TROWARA data were averaged from 11:00 to 13:00 UT and 23:00 to 01:00 UT, respectively, in order to best match the radiosonde measurement times. The radiosonde profiles are integrated from the surface to $200 \mathrm{mb}$, RS (s-200), for comparison with TROWARA and from 850 to $200 \mathrm{mb}$, RS (850 200), for comparison with ECMWF. The numerical values of the trends according to Fig. 6 are listed in Table 1 .

It is generally accepted that a trend is at least significant at the $90 \%$ and $95 \%$ levels if the trend divided by the standard error equals or exceeds 1.65 and 1.96 , respectively. The significance indicates the confidence with which a change in the measurements can be distinguished from natural variability or measurement noise, but it does not give information on whether long-term changes can be distinguished from periodic oscillations in the climate system. The RS (s-200) and (850-200) midnight trends of $0.087 \pm 0.046$ and $0.056 \pm 0.032 \mathrm{~mm} / \mathrm{y}$ are significant at the $90 \%$ level. The TROWARA midday trend $(0.098 \pm 0.061 \mathrm{~mm} / \mathrm{y})$ and $\mathrm{RS}(\mathrm{s}-$ $200)$ trend $(0.068 \pm 0.043 \mathrm{~mm} / \mathrm{y})$ for all observations are significant at the $89 \%$ level. 


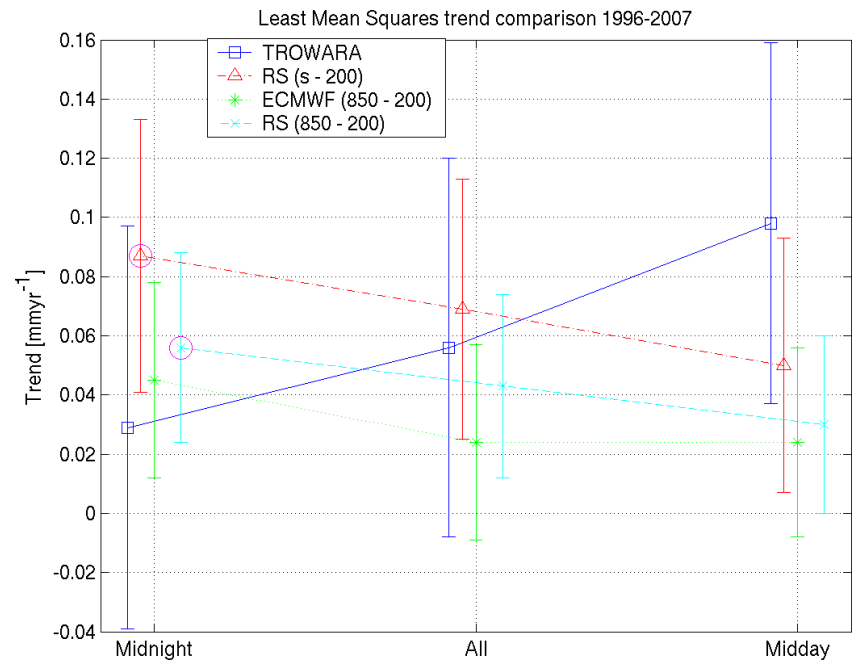

Fig. 6. Yearly trends in IWV in mm calculated for the 1996-2007 period. The error bars show the standard error and the large circles indicate that a trend is significant at the $90 \%$ level. The datasets are plotted with a slight offset along the $\mathrm{x}$-axis so that error bars can be distinguished.

Table 1. Intercomparison of IWV trends $[\mathrm{mm} / \mathrm{y}]$ for the time interval 1996-2007 for TROWARA radiometer at Bern, Payerne radiosonde from surface to $200 \mathrm{hPa}$ pressure level (RS(s-200)), ECMWF operational analysis from 850 to $200 \mathrm{hPa}$, and Payerne radiosonde from 850 to $200 \mathrm{hPa}$ pressure level $(\operatorname{RS}(850-200))$. A diagram of the table is depicted in Fig. 6.

\begin{tabular}{lccc}
\hline & midnight & all & midday \\
\hline TROWARA & $0.030 \pm 0.068$ & $0.056 \pm 0.064$ & $0.098 \pm 0.061$ \\
RS (s-200) & $0.087 \pm 0.046$ & $0.068 \pm 0.043$ & $0.045 \pm 0.043$ \\
ECMWF & $0.045 \pm 0.033$ & $0.024 \pm 0.032$ & $0.024 \pm 0.031$ \\
RS (850-200) & $0.056 \pm 0.032$ & $0.043 \pm 0.030$ & $0.030 \pm 0.029$ \\
\hline
\end{tabular}

The ECMWF trends, although not significant, are somewhat lower than the radiosonde trends, but show the same behavior in that midnight trends are larger than midday trends. TROWARA, which contains more measurement times in the all day dataset, shows the opposite behavior. The difference is probably not caused by the radiosonde solar radiation error, because changes in processing techniques would have tended to produce a slight increase in the radiosonde daytime trend and do not explain the large nighttime trend. On the other hand, the disagreement could be due to the fact that TROWARA was moved indoors in late 2002. This stabilised the internal air temperature. It could be that the large diurnal changes which occurred in the radiometer air temperature when it was outdoors had a differing effect on midday and midnight data. If the period 2003 to 2007 is analysed, when the instrument was only operated indoors, then a nighttime trend of $0.10 \pm 0.21 \mathrm{~mm} / \mathrm{y}$ and a daytime trend of
$0.07 \pm 0.19 \mathrm{~mm} / \mathrm{y}$ are calculated. The radiosonde trends for the same 2003 to 2007 period are $0.29 \pm 0.17 \mathrm{~mm} / \mathrm{y}$ at nighttime and $0.18 \pm 0.14 \mathrm{~mm} / \mathrm{y}$ at daytime. The quite different trend values for both measuring methods can be attributed to the short analysed period (5 years) including a particularly warm summertime during the first year (2003). The nighttime trends of both TROWARA and Payerne radiosondes are however stronger than the corresponding daytime trends. A higher nighttime than daytime trend in water vapour is consistent with the fact that minimum surface air temperatures have increased faster than maximum temperatures in the period between 1950 and 2004 (Vose et al., 2005).

An average temperature trend of $0.06 \pm 0.05 \mathrm{~K} / \mathrm{y}$ was calculated for 1996-2007 using the Basel, Bern, Chaumont, Geneva and Zürich homogenized temperature series (Begert et al., 2005). Under the assumption of constant relative humidity, the expected water vapour increase is $0.36 \pm 0.30 \% / y$. In comparison, trends of $0.25 \pm 0.34$, $0.39 \pm 0.44$ and $0.45 \pm 0.29 \% / y$ were calculated for ECMWF, TROWARA and RS (s-200) IWV. The results are consistent with the change predicted by the surface temperature increase, but a longer time period is required for statistically significant results and to determine the cause of the water vapour increase.

Calculating the TROWARA trends over the longer period 1994-2007, produces a slightly larger trend of $0.43 \pm 0.33 \% / y$. Adding the first ten months of 2008 to the 1996-2007 series produces a similar trend of $0.41 \pm 0.37 \% / y$. From this it can be concluded that the TROWARA trends are not greatly sensitive to the endpoints.

\subsection{Mann Kendall analysis}

The Mann Kendall (MK) technique allows monthly or seasonal trends to be calculated. It was corrected for autocorrelation in the data (Hamed and Rao, 1998) and trend magnitude was determined using the Sen's slope estimator (Sen, 1968). Figure 7 shows the monthly trends calculated using all observation times. The absolute values are larger than the LSA trends calculated for the full year because of compensating trends in winter and summer. In December to March, the trends are close to zero or negative in agreement with the findings of Nilsson and Elgered (2008). December is the only winter month with a statistically significant trend of $-0.20 \pm 0.14$ and $-0.36 \pm 0.24 \mathrm{~mm} / \mathrm{y}$ for ECMWF and TROWARA, respectively, which is equivalent to $-3.6 \pm 2.5$ to $-4.3 \pm 2.9 \% / y$. Positive trends are seen from April to October, with the exception of August, which has a negative trend. July is the only month showing a positive statistically significant trend for all datasets of $0.19 \pm 0.14$ to $0.34 \pm 0.25 \mathrm{~mm} / \mathrm{y}$ or $+1.2 \pm 0.8$ to $1.6 \pm 1.1 \% / \mathrm{y}$.

The negative trend seen in all datasets in August could be due to the surface moisture drying out and reducing evaporation. This tendency was observed by Guerova and Morland (2008) in a study of GPS and radiosonde IWV during the 


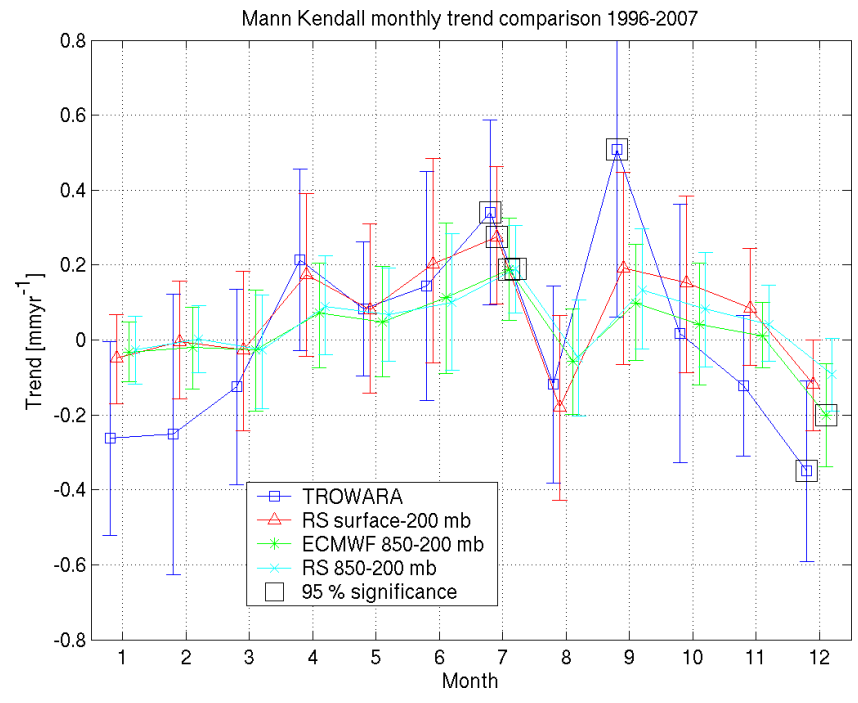

Fig. 7. Monthly trends for the 1996-2007 period calculated using the Mann Kendall analysis for all observation times. The large squares indicate trends which are significant at the $95 \%$ level. The datasets are plotted with a slight offset along the $\mathrm{x}$-axis so that error bars can be distinguished.

summer 2003 heatwave. However, an analysis of the time series of precipitation in Switzerland revealed an increase of precipitation in August, particularly during the last three years from 2005 to 2007 . Since precipitation is a sink for atmospheric water vapour, the positive trend of precipitation in August may induce the negative trend of IWV in August. A combined trend analysis of IWV, precipitation, and surface moisture could reveal persistent changes of the water cycle, but this is beyond the scope of the present study.

The trend directions are in agreement for every month except November for which the trends are not significant for any dataset. In September, TROWARA shows a stronger positive trend than the other datasets and in December to March a stronger negative trend. To test whether this was due to the gaps in the TROWARA dataset, a trend analysis was carried out on the radiosonde data for only the months during which a TROWARA monthly mean was also available. The RS (s-200) trends calculated using the masked dataset were closer to the TROWARA trends for March and September, but did not greatly differ from the unmasked dataset for December to February. The more negative winter trends for TROWARA may be due to a real difference between Payerne and Bern or to an undetected instrumental effect.

When midday or midnight trends are examined with the MK technique, the same pattern is seen as with the LSA in that midnight trends are higher than midday trends for ECMWF and radiosonde, whilst the opposite is true for TROWARA. The ECMWF and TROWARA trends are on average 0.02 and $0.06 \mathrm{~mm} / \mathrm{y}$ lower than radiosonde trends with standard deviations of 0.03 and $0.17 \mathrm{~mm} / \mathrm{y}$, respectively. It is not surprising that the radiosonde agrees better with ECMWF than with TROWARA because the Payerne radiosonde data are assimilated in the operational analysis.

\section{Conclusions}

Homogenisation techniques, which were originally developed for temperature and precipitation measurements, were applied to the TROWARA IWV data. The reference series were the Payerne radiosonde and IWV calculated for the atmospheric layer between weather stations separated by 380 to $420 \mathrm{~m}$ altitude. Changepoints due to known instrument problems were confirmed and an additional break in the series, associated with a gap in measurements, was identified for which no instrument information had been recorded. The original TROWARA time series was corrected with the help of the changepoint magnitudes identified by the homogenisation techniques as well as comparison with simultaneous radiosonde, GPS and SPM data. The differences between the corrected TROWARA data and radiosonde, GPS and SPM data IWV lay between $\pm 0.6 \mathrm{~mm}$.

An analysis of the 1996 to 2007 monthly climatology of several datasets revealed that sampling differences can cause significant variation in the monthly means. The SPM, which is restricted to sunny conditions, has a negative bias of around 20\% IWV compared to TROWARA. On the other hand the GPS, which can measure in all weather conditions, has a positive bias of 7 to $17 \%$ compared to TROWARA monthly means. GPS and TROWARA data obtained in non-raining conditions showed that less than half of this bias was due to measurement differences between the instruments. The remaining bias is attributed to the fact that only TROWARA data obtained in non-raining conditions were included in this analysis. Due to its sheltered location, TROWARA has been able to measure in some, but not all, light rain conditions since 2003. Care must be taken not to introduce an artificial positive trend if these data are included in a future trend analysis.

A diurnal cycle in TROWARA IWV was detected which had an amplitude of $0.32 \mathrm{~mm}$, a maximum beween 19:00 and 21:00 UT and a minimum at 11:00 UT. A comparison with GPS data showed that calculating GPS IWV without damping the diurnal cycle in the surface air temperature produces an IWV cycle which is shifted one or two hours earlier than the TROWARA cycle. Damping or removing the diurnal cycle from the surface air temperature used in the GPS Zenith Total Delay to IWV conversion, leads to a much better match with the TROWARA diurnal cycle. ECMWF data match the TROWARA diurnal cycle reasonably well considering that there are only four datapoints each day. The radiosonde, however, produces an unreasonably large amplitude in the IWV diurnal cycle and this was attributed to an underestimate of IWV at midday when the radiosonde is heated by solar radiation. 
Using least squares analysis, the three datasets showed consistent positive trends in IWV from 1996 to 2007 (Table 1). The Payerne radiosondes (RS s-200) measured an IWV trend of $0.45 \pm 0.29 \% / y$, the TROWARA radiometer observed a trend of $0.39 \pm 0.44 \% / y$, and ECMWF operational analysis gave a trend of $0.25 \pm 0.34 \% / y$. Table 1 also contains the trends for midnight and midday observations which are also positive.

Since IWV has a strong and variable annual cycle, a seasonal trend analysis (Mann-Kendall analysis, Fig. 7) was performed. The seasonal trends are stronger by a factor 10 or so compared to the full year trends above. The strong seasonal trends of IWV on a regional scale underline the necessity of long-term monitoring of IWV for detection, understanding, and forecast of climate change effects in the Alpine region. The positive IWV trends of the summer months are partly compensated by the negative trends of the winter months. All datasets indicated a significant positive trend in July. TROWARA and ECMWF showed a significant negative trend in December. The TROWARA radiometer observed a positive IWV trend of $1.6 \pm 1.1 \% / y$ in July, the ECMWF operational analysis indicated an IWV trend of $1.3 \pm 0.8 \% / y$, and the Payerne radiosondes (RS s-200) measured a trend of $1.3 \pm 1.8 \% / y$ in July. The negative December trends were: $-4.3 \pm 2.9 \% / y$ for TROWARA, $-3.6 \pm 2.5 \% / y$ for ECMWF operational analysis, and $-1.2 \pm 1.2 \% / y$ for the Payerne radiosondes. A curiosity was the negative IWV trend in August (Fig. 7) which might be due to a positive precipitation trend in August.

The radiosonde midnight trend was significant at the $90 \%$ level whilst the TROWARA midday trend and radiosonde trend for all observations were significant at the $89 \%$ level. The seasonal Mann Kendall analysis showed trends of the same direction for all three datasets for all months except November, which was not statistically significant.

To detect a trend at the 95\% significance level, 13, 15 and 20 full years of data are required for the radiosonde, TROWARA and ECMWF datasets, respectively, according to the method of Weatherhead (2000). Establishing the statistical significance of a trend and determining its cause are two quite different tasks. Observations over several decades are necessary to distinguish anthropogenic influences from decadal oscillations in the climate system. For this reason, it is very important to continue to collect, quality control and homogenise water vapour data for climate research.

In addition, there is potential to improve the retrieval of TROWARA IWV. A new algorithm developed by Mätzler and Morland (2009) can better estimate ILW (Integrated Liquid Water). The data from the old algorithm, based on the work of Wu (1979), are still being saved in order to allow comparisons between the two products. Based on an analysis of one year of data, the new algorithm has a bias of only $+0.02 \mathrm{~mm}$ in IWV relative to the old one, which is promising for its use in future climate research.
Acknowledgement. This work was supported by NCCR Climate. The help of E. Graham, L. Martin and the IAP Electronics Workshop in operating and maintaining TROWARA is greatly appreciated. We acknowledge MeteoSwiss and Swisstopo for providing the meteorological and GPS data.

Edited by: H. Wernli

\section{References}

Alexandersson, H.: A homogeneity test applied to precipitation data, J. Climatol., 6, 661-675, 1986.

Begert M., Schlegel, T., and Kirchhofer, W.: Homogeneous temperature and precipitation series of Switzerland from 1864 to 2000, Int. J. Climatol., 25, 65-80, doi:10.1002/joc.1118, 2005.

Bevis, M., Businger, S., Herring, T. A., Rocken, C., Anthes, R. A., and Ware, R. H.: GPS Meteorology: Remote sensing of atmospheric water vapor using the global positioning system, J. Geophys. Res., 97(D14), 15787-15801, 1992.

Collaud Coen, M., Weingartner, E., Nyeki, S., Cozic, J., Henning, S., Verheggen, B., Gehrig, R., and Baltensperger, U.: Long-term trend analysis of aerosol variables at the highalpine site Jungfraujoch, J. Geophys. Res., 112, D13213, doi:10.1029/2006JD007995, 2007.

Dai A., Wang, J., Ware, R. H., and Van Hove, T.: Diurnal variation in water vapor over North America and its implications for sampling errors in radiosonde humidity, J. Geophys. Res., 107(D10), 4090, doi:10.1029/2001JD000642, 2002.

Deuber, B., Morland, J., Martin, L. and Kämpfer, N.: Deriving the tropospheric integrated water vapor from tipping curve-derived opacity near $22 \mathrm{GHz}$, Radio Sci., 40, RS5011, doi:10.1029/2004RS003233, 2005.

Guerova, G., Brockmann, E., Quiby, J., Schubiger, F., and Mätzler, C.: Validation of NWP mesoscale models with Swiss GPS Network AGNES, J. Appl. Meteorol., 42(1), 141-150, 2003.

Guerova, G., Brockmann, E., Schubiger, F., Morland, J., and Mätzler C.: An integrated assessment of measured and modeled integrated water vapor in Switzerland for the period 2001-2003, J. Appl. Meteorol., 44(7), 1033-1044, 2005.

Guerova, G. and Morland, J.: Water vapour anomaly during the 2003 summer in Switzerland, AGU Chapman Conference, Hawaii, USA, 20-24 October, 2008.

Güldner, J. and Spänkuch, D.: Results of year-round remotely sensed integrated water vapor by ground-based microwave radiometry, J. Appl. Meteor., 38, 981-988, 1999.

Haas, R., Elgered, G., Johansson, J., and Gradinarsky, L.: Assessing Long Term Trends in the Atmospheric Water Vapor Content by Combining Data from VLBI, GPS, Radiosondes and Microwave Radiometry, in Proceedings of 16th Working Meeting on European VLBI for Geodesy and Astrometry, edited by: Schwegmann, W. and Thorandt, V., Bundesamt für Kartographie und Geodäsie, Frankfurt/Leipzig, 279-288, 2003.

Haefele, A., Hocke, K., Kämpfer, N., Keckhut, P., Marchand, M., Bekki, S., Morel, B., Egorova, T., and Rozanov, E.: Diurnal changes in middle atmospheric $\mathrm{H}_{2} \mathrm{O}$ and $\mathrm{O}_{3}$ : Observations in the Alpine region and climate models, J. Geophys. Res., 113, D17303, doi:10.1029/2008JD009892, 2008 
Hagemann S., Bengtsson, L., and Gendt, G.: On the determination of atmospheric water vapor from GPS measurements, J. Geophys. Res., 108(D21), 4678, doi:10.1029/2002JD003235, 2003.

Hall, A. and Manabe, S.: The role of water vapor feedback in Unperturbed Climate Variability and Global Warming, J. Climate, 12, 2327-2346, 1999.

Hamed, K. A. and Rao, A. R.: A modified Mann-Kendall trend test for autocorrelated data, J. Hydrol., 204, 182-196, 1998.

Hirsch, R. M. and Slack, J. R.: A nonparametric trend trest for seasonal data with serial dependence, Water Resour. Res., 20, $727-$ $732,1984$.

Ingold, T. and Mätzler, C.: Four Years of Columnar Water Vapor Measurements above the Swiss Central Plain using Radiosondes and a Microwave Radiometer, Research Report No. 2000-2002, Institute of Applied Physics, University of Bern, Switzerland, 26 pp., 2000.

Ingold, T., Schmid, B., Matzler, C., Demoulin, P., and Kampfer, N.: Modeled and empirical approaches for retrieving columnar water vapor from solar transmittance measurements in the 0.72 , 0.82 and $0.94 \mathrm{~m}$ absorption bands, J. Geophys. Res., 105(D19), 24327-24344, doi:10.1029/2000JD900392, 2000.

Jeannet, P., Ruffieux, D., Nater, R., Berger, H., Levrat, G., and Hewison, T.: Temperatur- und Feuchtigkeitsprofile: Vergleich von Radiosonden und Bodengestuetzten Fernerkundungsystem, Proceedings of DACH 2004 Meteorologentagung, 7-10 September 2004, Karlsruhe, Germany, 2004.

Kistler, R. and Coauthors: The NCEP-NCAR 50-year reanalysis: monthly means CD-ROM and documentation, B. Amer. Meteorol. Soc., 82, 247-267, 2001.

Martin, L., Mätzler, C., Hewison, T. J., and Ruffieux, D.: Intercomparison of integrated water vapour measurements, Meteorol. Z., 15, 57-64, 2006.

Mätzler, C. and Martin, L. and Guerova, G. and Ingold, T.: Assessment of integrated-water-vapour data at Bern from GPS, sun photometry, microwave radiometry and radiosonde, COST-716 contribution, available at: http://www.iap.unibe.ch/publications, 2002.

Mätzler, C. and Morland, J.: Refined Physical Retrieval of Integrated Water Vapour and Cloud Liquid for Microwave Radiometer Data, IEEE T. Geosci. Rem. Sens., 47(6), 1585-1594, 2009.

Miloshevich L. M., Vömel, H., Whiteman, D. N., Lesht, B. M., Schmidlin, F. J., and Russo, F.: Absolute accuracy of water vapor measurements from six operational radiosonde types launched during AWEX-G and implications for AIRS validation, J. Geophys. Res., 111, D09S10, doi:10.1029/2005JD006083, 2006.

Morland, J.: TROWARA - Tropospheric Water Vapour Radiometer. Radiometer review and new calibration model, Research Report No. 2002-15-MW, Institute of Applied Physics, University of Bern, Switzerland, 29 pp., 2002.

Morland, J.: TROWARA - rain flag development and stability of instrument and calibration,, Research Report No. 2007-13-MW, Institute of Applied Physics, University of Bern, 45 pp., 2007.

Morland, J. and Mätzler, C.: Spatial interpolation of GPS integrated water vapour measurements made in the Swiss Alps, Meteorol. Appl., 14, 15-26, 2007.

Morland, J. , Liniger, M. A., Kunz, H., Balin, I., Nyeki, S., Mätzler, C. and Kämpfer, N.: Comparison of GPS and ERA40 IWV in the Alpine region, including correction of GPS observations at Jungfraujoch (3584 m), J. Geophys. Res., 111, D04102,
doi:10.1029/2005JD006043, 2006a.

Morland, J. , Deuber, B., Feist, D. G.., Martin, L., Nyeki, S., Kämpfer, N., Mätzler, C., Jeannet, P., and Vuilleumier, L.: The STARTWAVE atmospheric water database, Atmos. Chem. Phys., 6, 2039-2056, 2006b, http://www.atmos-chem-phys.net/6/2039/2006/.

Nilsson, T. and Elgered, G.: Long-term trends in the atmospheric water vapor content estimated from ground-based GPS data, J. Geophys. Res., 113, D19101, doi:10.1029/2008JD010110, 2008.

Nyeki, S., Vuilleumier, L., Morland, J., Bokoye, A., Viatte, P., Mätzler, C., and Kämpfer, N.: A 10-year integrated atmospheric water vapor record using precision filter radiometers at two high-alpine sites, Geophys. Res. Lett., 32 L23803, doi:10.1029/2005GL024079, 2005.

Peter, R. and Kämpfer, N.: Radiometric Determination of Water Vapor and Liquid Water and Its Validation With Other Techniques, J. Geophys. Res., 97(D16), 18173-18183, 1992.

Press, W. H., Teukolsky, S. A., Vetterling, W. T., and Flannery, B. P.: Numerical Recipes in C: the art of scientific computing, Second Edition, Cambridge University Press, 1992.

Revercomb, H. E., Turner, D. D., Tobin, D. C., Knuteson, R. O., Feltz, W. F., Barnard, J., Bösenberg, J., Clough, S., Cook, D., Ferrare, R., Goldsmith, J., Gutman, S., Halthore, R., Lesht, B., Liljegren, J., Linné, H., Michalsky, J., Morris, V., Porch, W., Richardson, S., Schmid, B., Splitt, M., Van Hove, T., Westwater, E., and Whiteman, D.: The ARM program's water vapor intensive observation periods, B. Am. Meteor. Soc., 84(2), 217236, 2003.

Rohrbach, A.: Wasserdampfmessungen mit GPS, Master thesis, Phil.-Nat. Faculty, University of Bern, Bern, Switzerland, 1999.

Ross, R. J. and Elliott, W. P.: Tropospheric water vapor climatology and trends over North America: 1973-1993, J. Climate, 9, 35613574, 1996.

Ross, R. J. and Elliott, W. P.: Radiosonde-based Northern Hemisphere tropospheric water vapor trends, J. Climate, 14, 16021612, 2001.

Sen, P. K.: Estimates of the regression coefficient based on Kendall's tau, J. Am. Statist. Assoc., 63, 1379-1389, 1968.

Trenberth, K. E., Fasullo, J., and Smith, L.: Trends and variability in column-integrated atmospheric water vapor, Clim. Dynam., 24(7-8), 741-758, doi:10.1007/s00382-005-0017-4, 2005.

Vey, S., Dietrich R., Fritsche, M., Rülke, A., Steigenberger, P. and Rothacher, M.: On the homogeneity and interpretation of precipitable water time series derived from global GPS observations, J. Geophys. Res., 114, D10101, doi:10.1029/2008JD010415, 2009.

Vincent, L. A.: A technique for the identification of inhomogeneities in canadian temperature series, J. Climate, 11, 1094 1104, 1998.

Vose, R. S., Easterling, D. R., and Gleason, B.: Maximum and minimum temperature trends for the globe: An update through 2004, Geophys. Res. Lett., 32, L23822, doi:10.1029/2005GL024379, 2005.

Wang J. and Zhang, L.: Systematic Errors in Global Radiosonde Precipitable Water Data from Comparisons with Ground-Based GPS Measurements, J. Clim., 21, 2218-2238, 2009.

Wang J., Zhang, L., and Dai, A.: Global estimates of water-vapor-weighted mean temperature of the atmosphere for GPS applications, J. Geophys. Res., 110, D21101, doi:10.1029/2005JD006215, 2005. 
Weatherhead, E. C., Reinsel, G. C., Tiao, G. C., Jackman, C. H., Bishop, L., Hollandsworth Frith, S. M., DeLuisi, J., Keller, T., Oltmans, S. J., Fleming, E. L., Wuebbles, D. J., Kerr, J. B., Miller, A. J., Herman, J., McPeters, R., Nagatani, R. M., and Frederick, J. E.: Detecting the recovery of total column ozone, J. Geophys. Res., 105(D17), 22201-22210, doi:10.1029/2000JD900063, 2000.
Wu, S. C.: Optimum frequencies of passive microwave radiometer for tropospheric path length correction, IEEE T. Ant. Prop., AP27, 233-239, 1979. 